\title{
Embates da descolonialidade e as pautas (não tão) ocultas dos
} museus: "A Cor do Brasil" no Museu de Arte do Rio

Clashes of decoloniality and the (not so) hidden agendas of museums: "A Cor do Brasil" at the Rio Art Museum

Enfrentamientos de la decolonialidad y las pautas (no tan) ocultas de los museos: "A Cor do Brasil" en el Museo de Arte de Río

\author{
Luiz Sérgio de Oliveira \\ Instituição: Universidade Federal Fluminense \\ E-mail: luizsergiodeoliveira.br@gmail.com \\ ORCID: https://orcid.org/0000-0002-8616-5089
}

RESUMO:

Em um cenário em que a arte se tornou política, uma questão fundamental se impõe: entender o lugar dessa arte política. Para muitos, os espaços apropriados para a instauração da arte, de qualquer arte, continuam sendo as instituições, em especial o museu e suas exposições, apesar das contradições sociais que norteiam suas políticas e ações. Neste estudo ${ }^{1}$, com base nas incisões descoloniais de Walter Mignolo, Anibal Quijano, Eduardo Viveiros de Castro e Pedro Pablo Gómez, buscamos investigar as complexidades envolvidas na construção e na recepção da mostra "A Cor do Brasil", realizada no Museu de Arte do Rio, entre 2016 e 2017, tendo como pano de fundo os processos da descolonialidade.

Palavras-chave: Arte. Museus. Descolonialidade. "A Cor do Brasil". Museu de Arte do Rio.

OLIVEIRA, Luiz Sérgio de. Embates da descolonialidade e as pautas (não tão) ocultas dos museus: "A Cor do Brasil" no Museu de Arte do Rio.

PÓS:Revista do Programa de Pós-graduação em Artes da EBA/UFMG. v.10, n.20: nov.2020

Disponível em < https://doi.org/10.35699/2237-5864.2020.19685/> 


\section{ABSTRACT:}

In a scenario where art has become political, a fundamental issue is raised: understanding the place of this political art. For many, the appropriate spaces for the establishment of art, of any art, remain being the art institutions, especially the museum and its exhibitions, despite the social contradictions that guide their policies and actions. In this study, based on the decolonial incisions of Walter Mignolo, Anibal Quijano, Eduardo Viveiros de Castro and Pedro Pablo Gómez, we sought to investigate the complexities involved in the construction and reception of the exhibition "A Cor do Brasil", held at the Rio Art Museum between 2016 and 2017, against the background of the processes of decoloniality.

Keywords: Art. Museums. Decoloniality. "A Cor do Brasil". Rio Art Museum.

\section{RESUMEN:}

En un escenario donde el arte se ha vuelto político, se plantea una cuestión fundamental: comprender el lugar de este arte político. Para muchos, los espacios apropiados para el establecimiento del arte, de cualquier arte, siguen siendo las instituciones artísticas, especialmente el museo y sus exposiciones, a pesar de las contradicciones sociales que guían sus políticas y acciones. En este estudio, basado en las incisiones descoloniales de Walter Mignolo, Anibal Quijano, Eduardo Viveiros de Castro y Pedro Pablo Gómez, buscamos investigar las complejidades involucradas en la construcción y recepción de la exposición "A Cor do Brasil", realizada en el Museo de Arte de Río entre 2016 y 2017, en el contexto de los procesos de descolonialidad.

Palabras clave: Arte. Museos. Descolonialidad. "A Cor do Brasil". Museo de Arte de Rio. 


\section{Arte e política no reverso do contemporâneo}

Os museus de arte são, por natureza, espaços politicamente controlados que, pela verticalização de suas relações institucionais, tentam se manter distanciados das tensões sociais e políticas do mundo real. Por outro lado, talvez mais do que nunca, arte e política têm andado de mãos dadas, sendo uma das marcas mais acentuadas da arte contemporânea. Ou, dito de outra maneira, nas últimas décadas a arte tem se feito francamente política. Diante desse cenário, precisamos aqui demarcar o que tratamos como contemporâneo e como arte contemporânea: seria contemporânea simplesmente toda e qualquer arte produzida nos dias correntes? Seria isso o bastante para definir o contemporâneo? Para alguns, isso seria o suficiente, enquanto para outros, a definição soa bastante simplória ou definitivamente ingênua. Para Boris Groys, crítico e teórico da arte alemão,

o termo "arte contemporânea" não designa simplesmente a arte produzida em nossos dias. Mais que isso, a arte contemporânea de hoje demonstra como o contemporâneo, como tal, se mostra - o ato de apresentar o presente. Neste sentido, a arte contemporânea é diferente da arte moderna, que era voltada para o futuro, e também da arte pós-moderna, que foi uma reflexão histórica sobre o projeto moderno. A "arte contemporânea" contemporânea privilegia o presente em relação ao futuro e ao passado. Portanto, para caracterizar corretamente a natureza da arte contemporânea, parece necessário situá-la em sua relação com o projeto moderno e com sua reavaliação pós-moderna (GROYS, 2008, p. 71).

De acordo com Groys, o moderno não pode ser pensado desvinculado do conceito que the dá sustentação - a criatividade -, uma vez que o moderno está irremediavelmente comprometido com a invenção de um "novo" que aponta para o futuro. Dessa maneira, segundo Groys, o artista moderno tentou desconhecer o passado e se voltar incondicionalmente para o futuro na tentativa de antecipar um novo "novo". Para atuar na emergência desse novo, o artista rompeu com o passado que, cada vez mais, dele se aproximava como consequência de uma sucessão de novos que se tornavam desatualizados e que eram desqualificados como tal a cada novo dia, a cada nova temporada ou a cada ano novo. "Abolir tradições, romper com convenções, destruir a arte antiga e erradicar os valores desatualizados", lembra Groys, "eram os slogans do dia. A prática da vanguarda histórica esteve baseada na equação'negação é criação"' (GROYS, 2008, p. 71).

OLIVEIRA, Luiz Sérgio de. Embates da descolonialidade e as pautas (não tão) ocultas dos museus: "A Cor do Brasil" no Museu de Arte do Rio.

PÓS:Revista do Programa de Pós-graduação em Artes da EBA/UFMG. v.10, n.20: nov.2020 Disponível em < https://doi.org/10.35699/2237-5864.2020.19685/> 
Essa elaboração de Boris Groys parece se replicar em certa percepção que muitos têm do Brasil e de seu lugar no mundo, visto como um país-nação que é "gigante pela própria natureza [e cujo] futuro espelha essa grandeza", como apontam os versos do hino nacional. No Brasil, vivenciamos o mito do futuro, o mito do país do futuro, quando o Brasil encontraria seu destino e sua grandeza. Isso talvez explique estarmos sempre mirando o horizonte à espera de um futuro que nunca chega, na mesma medida em que negligenciamos nosso passado, como se ele existisse para ser deixado exatamente lá onde sempre esteve - esquecido no passado. Nosso olhar parece apontar sempre para frente, para uma frente imaginada, como se efetivamente existisse, como se desconhecêssemos a esfericidade do mundo. Um olhar fixo em um horizonte que se conjuga com uma noção de Ocidente e que nos aproximaria de uma Europa mítica, com a qual sonhamos e desejamos ombrear em termos de magnitude e de modernidade, sendo essa Europa "moderna" o modelo a perseguir. Ou, mais que isso, em uma abertura incondicional ao "outro", conforme enfatizado por Viveiros de Castro em relação aos Tupinambá, para quem o "outro não era um espelho, mas um destino" (VIVEIROS DE CASTRO, 2017, p. 190).

Comprometidos que somos com esse ethos que nos empurra sempre para frente, poderíamos acreditar em nós mesmos como modernos, não fosse a modernidade para nós um eterno devir, comparável ao esforço inglório de Sísifo.

Por outro lado, balizado pela ânsia de quem sempre espera o futuro, o Brasil parece descuidar de sua história política, social e cultural, de sua memória e de sua presença decisiva na América Latina, em um descolamento que fica evidenciado nas celebrações em torno do 12 de outubro, quando no Brasil, diferentemente dos vizinhos latino-americanos, a data não marca a resistência à invasão do europeu branco, independentemente das singularidades e das temporalidades da chegada por estas bandas de cá de Colombo e, mais tarde, Cabral. Ao contrário, o 12 de outubro no Brasil se divide entre as celebrações de sua santa-padroeira e o dia das crianças, a sugerir, mais uma vez, o mito que se renova ano após ano. Em nossa ânsia de sermos vistos e de nos vermos a nós mesmos como o "país do futuro", tentamos inventar nossa modernidade com o apagamento de nossa história e de nosso passado.

OLIVEIRA, Luiz Sérgio de. Embates da descolonialidade e as pautas (não tão) ocultas dos museus: "A Cor do Brasil" no Museu de Arte do Rio.

PÓS:Revista do Programa de Pós-graduação em Artes da EBA/UFMG. v.10, n.20: nov.2020 Disponível em < https://doi.org/10.35699/2237-5864.2020.19685/>

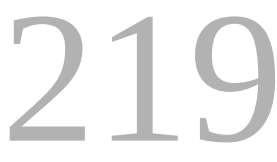


Por outro lado, em tempos mais recentes, artistas e ativistas brasileiros(as) têm reconhecido a urgência de trazer à luz os fantasmas de um passado colonial que permanece a arrodear nossos dias e nossos sonhos, como forma de resistir e de extirpar de nosso cotidiano político-socialcultural uma colonialidade renitente e obstinada que se recusa em nos deixar, presente tanto em pequenos gestos privados como em nossas práticas públicas. Independentemente se fomos ou não modernos, é necessário que nos aproximemos da noção de contemporâneo articulada pelo italiano Giorgio Agamben, mesmo que as trevas, no caso do Brasil, tenham sua matriz em um passado irresoluto:

Contemporâneo é aquele que mantém o olhar fixo no seu tempo, para nele perceber não as luzes, mas o escuro. Todos os tempos são, para quem deles experimenta a contemporaneidade, obscuros. Contemporâneo é, justamente, aquele que sabe ver essa obscuridade, que é capaz de escrever mergulhando a pena nas trevas do presente (AGAMBEN, 2012, p. 62-63).

No campo da arte, uma datação do contemporâneo permanece em disputa, quando não é simplesmente abandonada com certa indiferença. A britânica Claire Bishop, historiadora da arte e crítica, em uma tentativa de datar o que poderia ser entendido como contemporâneo na arte, afirma que até a década de 1990 a noção de contemporâneo se apresentava como quase sinônimo para o período que se seguiu ao término da Segunda Guerra Mundial. Já no início dos anos de 2000, um novo entendimento deslocava a emergência do contemporâneo para o início no anos de 1960, o que sofreria novo deslocamento mais recentemente: "atualmente as décadas de 1960 e 1970 tendem a ser vistas como o alto modernismo e o argumento apresentado é que devemos considerar 1989 como o início de uma nova era, sinônimo da queda do comunismo e do surgimento dos mercados globais" (BISHOP, 2013, p. 16).

Certamente, o ano de 1989 não pode ser visto como um ano qualquer diante das forças globais que levaram ao chão o muro de Berlim, cujos estrondos repercutem em nossas caixas cranianas como o big bang político-econômico-social-cultural fundamental do último quarto do século XX:

Todas as datas são convencionais, mas a de 1989 é um pouco menos convencional que as outras. A queda do Muro de Berlim simboliza, para todos os contemporâneos, a queda do socialismo. "Triunfo do liberalismo, do capitalismo, das democracias ocidentais sobre as vãs esperanças do marxismo", este é o comunicado vitorioso daqueles que escaparam por pouco do leninismo. (...) O Ocidente liberal não se contém de tanta alegria. Ele ganhou a guerra fria (LATOUR, 1994, p. 13-14).

OLIVEIRA, Luiz Sérgio de. Embates da descolonialidade e as pautas (não tão) ocultas dos museus: "A Cor do Brasil" no Museu de Arte do Rio.

PÓS:Revista do Programa de Pós-graduação em Artes da EBA/UFMG. v.10, n.20: nov.2020 Disponível em < $\underline{\text { https://doi.org/10.35699/2237-5864.2020.19685/> }}$

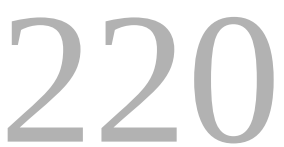


A onipresença do capitalismo a partir do fim das utopias em 1989, o que levaria a orientar todas as dimensões da vida contemporânea pela cartilha do mercado, não seria absorvida pelo mundo onde a vida é vivida sem que se emanasse resistência a cada um de seus movimentos. Assim, para cada reunião anual do fórum econômico em Davos, Suíça, demonstração de força do capitalismo global, os movimentos sociais mundializados buscam contrapor alternativas à força do capital global com as reuniões do fórum social mundial, manifestações que, frequentemente, transbordam em enfrentamentos com as forças policiais, como desde o primeiro fórum realizado em 2001, em Porto Alegre, Brasil.

Além disso, como se poderia imaginar e prever, a percepção de fracasso do comunismo como projeto civilizatório exerceu forte impacto sobre as artes e as humanidades. Entretanto, o entendimento de que o tempo presente é dominado pelas forças de um capitalismo ubíquo, antes de representar o apagamento das utopias, deflagrou deslocamentos que sinalizam para a emergência de utopias outras, nas quais a arte tem pelejado para garantir certo protagonismo e para reafirmar sua relevância em articulação com as imanências das coisas do mundo mundano.

\section{As pautas ocultas do museu imperial/colonial}

A tratarmos do museu ou, mais especificamente, do museu de arte no contemporâneo, partimos de um alerta que nos oferece Walter Mignolo, argentino que tem se dedicado aos estudos da descolonialidade, para quem os museus, assim como as universidades, permanecem cumprindo suas funções no processo de "reprodução da colonialidade do conhecimento e dos seres" (MIGNOLO, 2018, p. 310). Mignolo lembra que os museus, nos termos que ainda hoje são conhecidos, surgiram ainda no Renascimento atados à lógica da colonialidade, ou seja, comprometidos com a "necessidade de converter e civilizar os habitantes do planeta que ainda estavam fora da história, os bárbaros e os primitivos" (MIGNOLO, 2018, p. 311). Mignolo afirma que as instituições museais acabaram por se desdobrar em dois tipos básicos: o primeiro tipo, que inclui os museus de arte, "documentou e consolidou a genealogia da história europeia", enquanto o segundo tipo, "o museu etnográfico e natural, documentou 'outras culturas', incluindo sua arte" (MIGNOLO, 2018, p. 311).

OLIVEIRA, Luiz Sérgio de. Embates da descolonialidade e as pautas (não tão) ocultas dos museus: "A Cor do Brasil" no Museu de Arte do Rio.

PÓS:Revista do Programa de Pós-graduação em Artes da EBA/UFMG. v.10, n.20: nov.2020 Disponível em < https://doi.org/10.35699/2237-5864.2020.19685/>

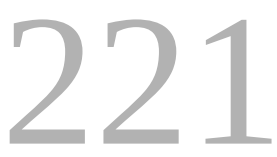


Os cinco séculos de modernidade, inaugurada com o Renascimento e com a expansão do capitalismo em escala global, são coincidentes e dependentes dos empreendimentos coloniais europeus, enquanto têm nos processos de colonialidade o seu lado mais sombrio, sua pauta oculta e o reverso de uma moeda que ata implacavelmente colonialidade à modernidade (MIGNOLO, 2017). Já para Anibal Quijano, sociólogo peruano, a colonialidade é um dos "elementos constitutivos e específicos do padrão mundial de poder capitalista", e

se baseia na imposição de uma classificação racial/étnica da população do mundo como pedra angular do dito padrão de poder, e opera em cada um dos planos, áreas e dimensões, materiais e subjetivas, da existência cotidiana e da escala social. Tem sua origem e se mundializa a partir da América. Com a constituição da América (Latina), no mesmo momento e no mesmo movimento histórico, o poder capitalista emergente se faz mundial (QUIJANO, 2014, p. 285-286).

Uma colonialidade que nos assombra e que nos domina nas diversas dimensões e esferas da vida cotidiana, tanto em suas manifestações públicas quanto em nossas ambiências mais privadas.

Em sua articulação com a colonialidade, a modernidade deve ser entendida como "um projeto de construção da imagem do mundo" (GÓMEZ, 2017, p. 29), sendo, portanto, um empreendimento de caráter estético: "sem a colonialidade estética, talvez as outras formas de colonialidade não tivessem sido possíveis, ou pelo menos teriam sido processos totalmente diferentes" (GÓMEZ, 2017, p. 30). Isso talvez nos ajude a compreender nossas dificuldades em pensar o mundo a partir de nós mesmos, a partir de uma episteme que contemple nossas percepções, crenças e mitos, e que nos afaste de narrativas que nos atravessam e que nos deixam encapsulados em outros mitos, como aquele que é a pedra fundamental da arte do Ocidente: o mito da universalidade da arte. Um mito que nos induz a acreditar que somente a partir da Europa, transmutada em centro absoluto do mundo moderno, é possível se escrever arte com A.

\section{Afinal, qual é a cor do Brasil?}

Os museus de arte, ao acolherem novos(as) visitantes, novas questões e novos conteúdos no universo museico, passaram eles mesmos a refletir os processos de retesamento político e social contemporâneo, tanto em sua face mais espetacular - as exposições de arte - quanto em disputas silenciosas em seus bastidores. Ao se abrirem para as políticas do cotidiano, os museus de arte acabaram por se ver abismados pelas tensões da descolonialidade que se esmiúçam por entre as

OLIVEIRA, Luiz Sérgio de. Embates da descolonialidade e as pautas (não tão) ocultas dos museus: "A Cor do Brasil" no Museu de Arte do Rio.

PÓS:Revista do Programa de Pós-graduação em Artes da EBA/UFMG. v.10, n.20: nov.2020

Disponível em < https://doi.org/10.35699/2237-5864.2020.19685/>

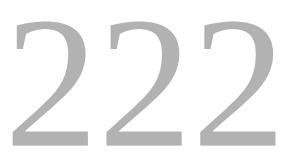


dimensões da vida pública e das relações privadas, refletindo tempos de fortes tensionamentos políticos e enfrentamentos identitários. Dessa maneira, as instituições museais, apesar de suas estruturas hierarquizadas, não conseguem evitar as reverberações das disputas descoloniais em suas entranhas.

Em um cenário marcado pela exacerbação dos preconceitos e pela permanência das desigualdades que caracterizam a sociedade brasileira, como se poderia pensar e apresentar a "cor do Brasil" em uma exposição de arte? Seria "a cor do Brasil" aquela que replica a exuberância dos trópicos, que faz com que as cores sejam mais viçosas e que o branco seja a soma de todas as cores sob a luz de um sol que nos cega a todos? Seria a "cor do Brasil" aquela policromia de gentes que nos constituem, gentes em peles de todas as cores, em especial a "gente de cor" que por séculos tem sido mantida na sombra, quando não nos porões da sociedade?

A curadoria da mostra "A Cor do Brasil", 2 realizada entre agosto de 2016 e janeiro de 2017 pelo Museu de Arte do Rio (MAR), com curadoria de Paulo Herkenhoff e Marcelo Campos, foi precedida de muitas expectativas tanto pelo título que carreia - "A Cor do Brasil" - como pelos históricos e as carreiras dos dois curadores, comprometidos com uma pauta inclusiva para o Museu de Arte do Rio, inaugurado na zona portuária da cidade do Rio de Janeiro a $1^{\circ}$ de março de 2013. Dois curadores com atuações e presença que reconhecem a relevância das pautas e das lutas identitárias nos desdobramentos da produção dos(as) artistas brasileiros(as). Diante desses históricos e desses compromissos, muito haveria de se esperar de "A Cor do Brasil".

Ainda na abertura da mostra, Paulo Herkenhoff, ao lado de Marcelo Campos, deu início a uma conversa/saudação ao público visitante com uma indagação instigante: "a pergunta que eu acho que se faz é se o Brasil é um país condenado à cor", em uma menção à carta de Pero Vaz Caminha, na qual aparecem referências "coloridas" a aspectos da flora, da fauna e dos adornos dos "brasis". ${ }^{3}$ Prosseguindo, Herkenhoff afirma:

é como se nosso batismo se fundasse em uma percepção europeia da cor; ou se a percepção europeia de cor tivesse sido determinada pelos donos da terra e, depois, reconfigurada pelo processo da escravidão. [Portanto] a primeira questão na cor do Brasil é entender que essa condenação à cor é irmã da condenação ao moderno de que nos falava Mário Pedrosa (MAR, 2016, vídeo).

OLIVEIRA, Luiz Sérgio de. Embates da descolonialidade e as pautas (não tão) ocultas dos museus: "A Cor do Brasil" no Museu de Arte do Rio.

PÓS:Revista do Programa de Pós-graduação em Artes da EBA/UFMG. v.10, n.20: nov.2020 Disponível em < https://doi.org/10.35699/2237-5864.2020.19685/>

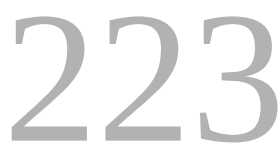


"O Brasil como um país condenado à cor": com que metáfora lidamos aqui? São referências corriqueiras às visualidades artísticas, em especial na obra de pintores ou pintoras, geralmente pintores, a excitar nossos nervos ópticos e nossos sentidos? Ou, ao contrário, o sentido seria outro, um que aponta para um país "condenado" à prevalência sem fim de uma única cor - a branca - nos planos social, cultural, político e econômico brasileiros, segregando e empurrando para as margens todos os outros matizes e nuanças de cor de pele e de culturas diversas daquele homem europeu que aportou por essas bandas de cá a partir de 1500? Os próprios curadores nos alertam logo na abertura do texto de apresentação do projeto curatorial de que "não há cor neutra", lembrando-nos, logo em seguida, de que "além de ser fenômeno óptico, a cor é construção social. Por atuar no campo do sensível, atua também politicamente" (HERKENHOFF; CAMPOS, 2016).

No entanto, já no segundo parágrafo do mesmo texto curatorial, Paulo Herkenhoff e Marcelo Campos tornam cristalino o escopo da curadoria, dedicada às investigações em torno da cor nas paletas da arte brasileira, em um processo que aponta plenamente para a autonomização da arte, mesmo que lateralmente se procurasse tratar de questões urgentes da arte e da cultura brasileiras, como o lugar e o papel das artes afro-brasileiras na constituição de uma ideia de Brasil que não seja eurocentrada e embranquecida por séculos de dominação e de subalternidade:

A exposição "A Cor do Brasil" apresenta percursos, inflexões e transformações da cor na história da arte brasileira. Ao iniciar com os projetos da cor dramática do barroco, a paleta cromática da natureza dos pintores viajantes dos séculos XVII-XIX, e as investigações acadêmicas afrancesadas, a mostra abre um largo panorama para as experimentações modernas em torno da cor no século XX (HERKENHOFF; CAMPOS, 2016).

Para evitar que as questões da afro-brasilidade fossem mantidas ao largo das preocupações centrais da curadoria de Herkenhoff e Campos (este, um professor, pesquisador e curador afrodescendente), foram incluídos artistas negros em diferentes núcleos temáticos, que organizavam a mostra na busca de dar-Ihe coerência e sentido. No entanto, conforme apontado por Hélio Santos Menezes Neto em pesquisa de mestrado junto à Universidade de São Paulo, a participação desses artistas não significou um adensamento das reflexões em torno do universo da afro-brasilidade:

OLIVEIRA, Luiz Sérgio de. Embates da descolonialidade e as pautas (não tão) ocultas dos museus: "A Cor do Brasil" no Museu de Arte do Rio.

PÓS:Revista do Programa de Pós-graduação em Artes da EBA/UFMG. v.10, n.20: nov.2020

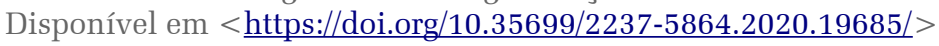

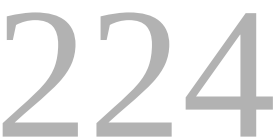


Antônio Bandeira, Arjan Martins, Arthur Bispo do Rosário, Arthur Timótheo da Costa, Ayrson Heráclito, Dalton Paula, Estêvão Silva, Heitor dos Prazeres, Jaime Lauriano e Leandro Joaquim (sec. XVIII) figuram entre estes artistas distribuídos pelo circuito expositivo, com obras que não necessariamente tematizavam questões afro-brasileiras (MENEZES NETO, 2018, p. 86).

Além dessas incisões pontuais em diferentes núcleos da mostra, o que poderia ser entendido como um instrumento de dispersão, os curadores criaram o núcleo de "Arte Afro-brasileira", que, modestamente, incluía obras tanto de artistas negros quanto de brancos em torno de temáticas que contemplariam o universo da negritude:

Esse núcleo apresentava uma configuração mais modesta. Localizado numa sala ou mais propriamente num corredor de passagem, conectando duas salas expositivas à escadaria do prédio - o núcleo de "Arte Afro-brasileira" trazia obras de artistas negros e brancos: três fotografias de Walter Firmo (retratando personalidades negras da música carioca: Pixinguinha, Cartola e Clementina de Jesus); quatro telas de Rubem Valentim; sete colares de conta estilizados de Júnior de Odé, cada um dedicado a um orixá; uma tela de Emanoel Araújo e outra de Carybé. O candomblé e o samba tematizavam quase a totalidade das obras reunidas, o único elo aliás entre trabalhos de suportes e faturas variados, e também realizados num amplo espaço temporal (da década de 1940 a 1990). A temática aparecia como critério isolado, e a ideia da cor como fio condutor da exposição encontrava, naquele arranjo, uma solução de difícil alcance (MENEZES NETO, 2018, p. 86).

Menos que uma sala, conforme apontado por Menezes Neto, o núcleo de arte afro-brasileira na mostra "A Cor do Brasil" ganhou uma configuração muito aquém de sua contribuição para a historiografia da arte brasileira, mesmo quando consideramos os aspectos excludentes e coloniais das narrativas que compõem a história da arte no Brasil. Essa lateralidade aparece consignada no projeto expográfico da mostra (Fig. 1 e Fig. 2).

OLIVEIRA, Luiz Sérgio de. Embates da descolonialidade e as pautas (não tão) ocultas dos museus: "A Cor do Brasil" no Museu de Arte do Rio.

PÓS:Revista do Programa de Pós-graduação em Artes da EBA/UFMG. v.10, n.20: nov.2020 Disponível em < $\underline{\text { https://doi.org/10.35699/2237-5864.2020.19685/> }}$

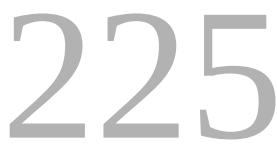




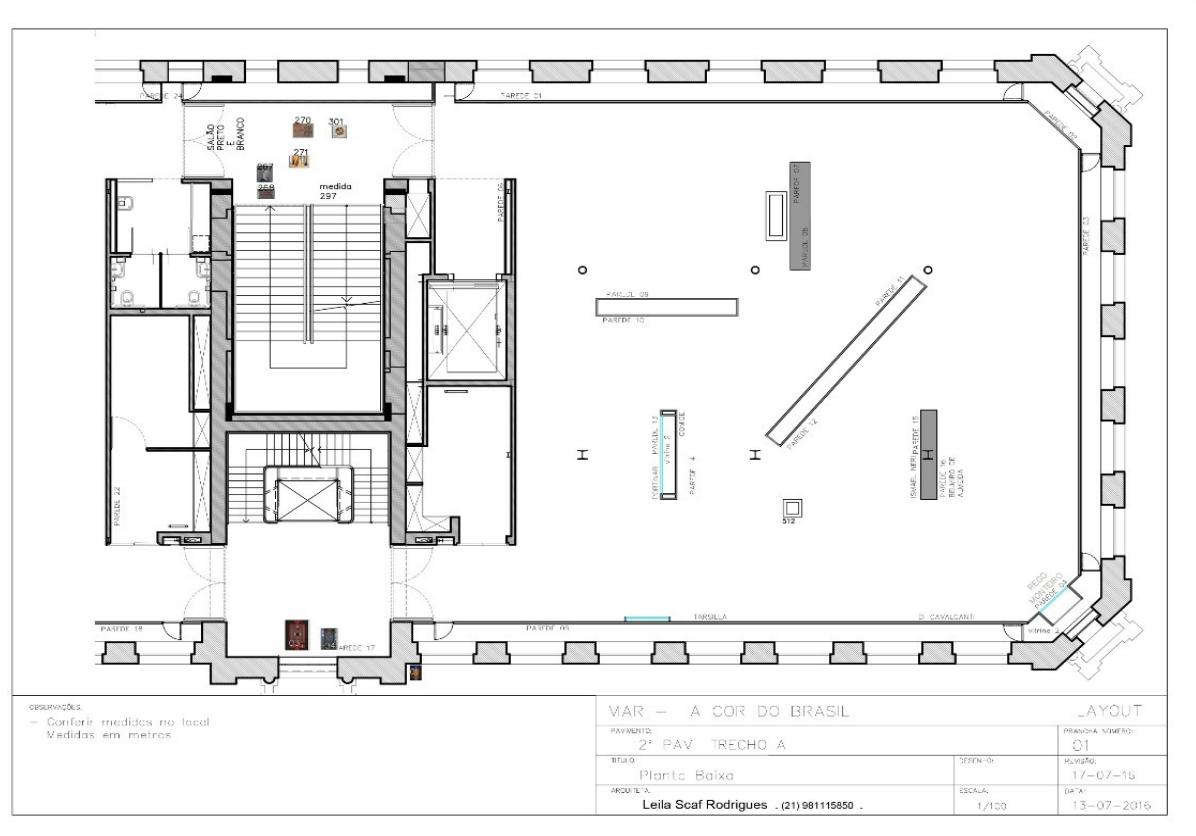

Fig. 1 - "A Cor do Brasil", projeto expográfico, sala 1-A3, Museu de Arte do Rio, 2016. planta baixa, 20 pavimento, trecho B - Arquiteta: Leila Scaf Rodrigues (17/7/2016)

Fonte: Arquivo do Museu de Arte do Rio, Rio de Janeiro

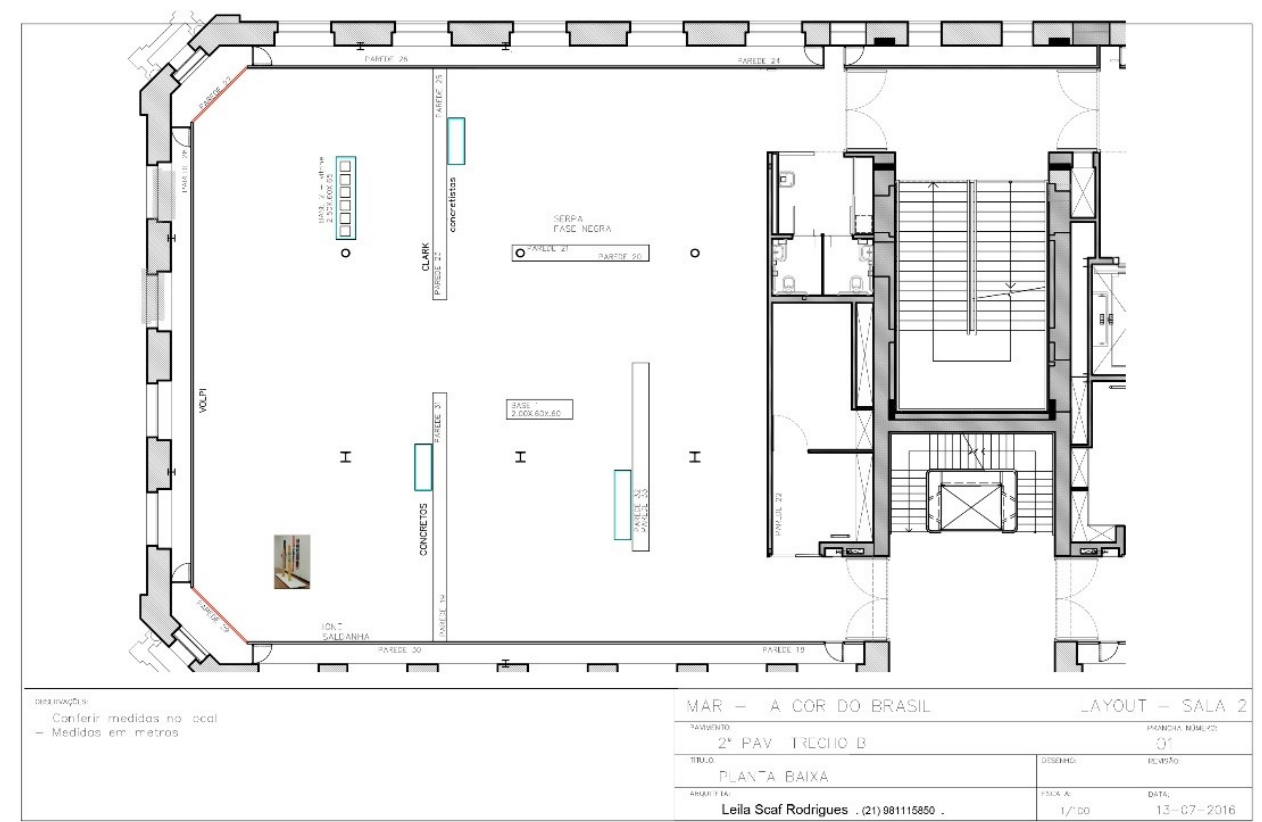

Fig. 2 "A Cor do Brasil", projeto
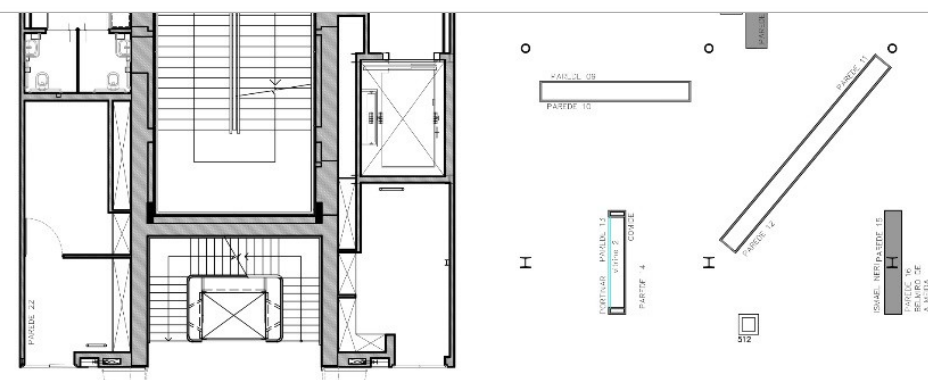
expográfico, sala 2-A3, Museu de Arte do Rio, 2016. planta baixa, $2^{\circ}$ pavimento, trecho B - Arquiteta: Leila Scaf Rodrigues (17/7/2016)

Fonte: Arquivo do Museu de Arte do Rio, Rio de Janeiro

"A Cor do Brasil" acabou por configurar-se como uma mostra enciclopédica a revelar a ambição do Museu de Arte do Rio e dos curadores de promover uma reescritura da arte brasileira a partir do elemento cor. Entretanto, a presença discreta e tímida de obras, artistas e debates que enfatizassem as contribuições das artes afro-brasileiras para a constituição da pluralidade da cultura brasileira pode ter deixado alguns visitantes e/ou pesquisadores com sentimentos mistos, embebidos em certa frustração e desapontamento. Por outro lado, não se pode desconhecer que essa situação que se evidencia e se replica em "A Cor do Brasil" não foi inventada pelos curadores da mostra, sendo, ao contrário, essa sub-representação de artistas negros, de mulheres e das minorias um déficit recorrente na arte brasileira, em suas coleções, em seus museus e, consequentemente, em sua historiografia. Essa é uma questão que permanece à espera de ser enfrentada, tanto pela necessidade de diminuição das desigualdades também no terreno das artes quanto pelas potencialidades de inventividade e de enriquecimento da percepção político-social-cultural de nós mesmos.

Afinal, a riqueza de nossa(s) cultura(s) reside justamente em sua policromia, nos cruzamentos e nos atravessamentos decorrentes da riqueza de matrizes que nos constituem, algo que não pode ser apagado em processos de obliterações e de derretimentos que mal escondem a opressão, os privilégios e a dominação em favor dos mecanismos da subalternidade. Algo que aparece de forma exemplarmente complexa no gesto de Waltércio Caldas ao deitar talco sobre um livro com as imagens do pintor e colorista francês Henri Matisse (Fig. 3), desdobrado em elaborações em textos relacionados à mostra "A Cor do Brasil":

O ato de Waltércio Caldas é simples: cobrir com talco um livro sobre Matisse, o artista da cor sensual e vibrante. Mas seu significado é complexo. Matisse com talco remete à história da ciência e da arte moderna e ao disco feito pelo físico Isaac Newton, um círculo pintado com as sete cores presentes na luz do sol (as do arcoíris). Quando o disco de Newton é posto em movimento, as cores se sobrepõem em nosso olho (na retina) e temos a sensação de mistura. Com a velocidade, vem a ilusão de o conjunto ter ficado cinza ou branco. (...) Em amplo sentido, Matisse com talco é o emblema que significa a própria "A Cor do Brasil", pois é a obra-chave que traz a hipótese imaginária de conjunção de todas as cores da exposição (MAR, 2016).

OLIVEIRA, Luiz Sérgio de. Embates da descolonialidade e as pautas (não tão) ocultas dos museus: "A Cor do Brasil" no Museu de Arte do Rio.

PÓS:Revista do Programa de Pós-graduação em Artes da EBA/UFMG. v.10, n.20: nov.2020 Disponível em < https://doi.org/10.35699/2237-5864.2020.19685/> 


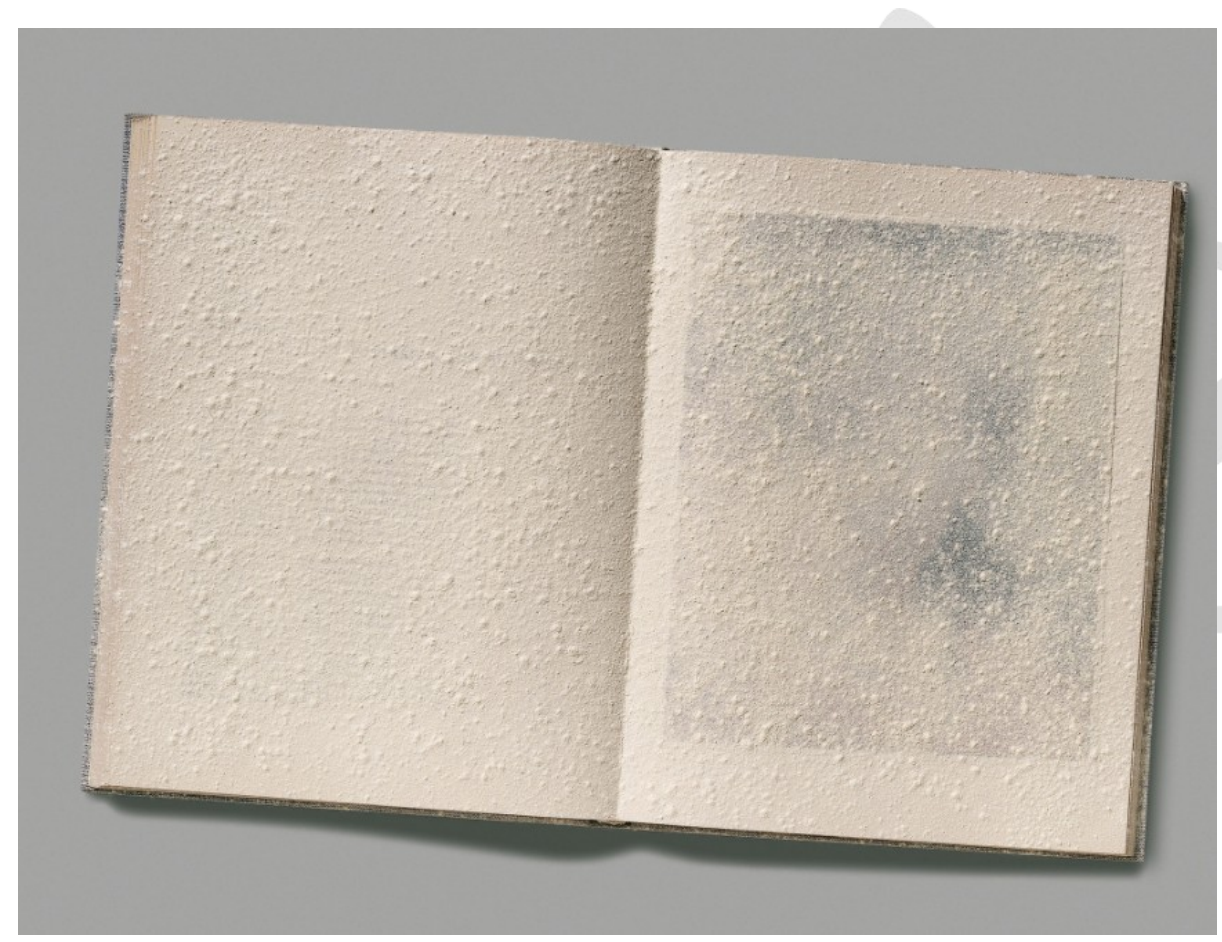

Fig. 3 - Waltércio Caldas, Matisse, Talco, 1978. $40 \mathrm{~cm}$ x $60 \mathrm{~cm}$ x $3 \mathrm{~cm}$, talco sobre livro ilustrado de Henri Matisse

Fonte: https://www.daros-latinamerica.net/artwork/matisse-talco/

\section{Considerações finais}

A ideia de harmonização de todas as cores vai na contramão da necessidade de enfatizarmos nossas singularidades, deixando que elas, em ricos processos de embates e de fricções, encontrem seus termos na afirmação de nossa pluriversalidade. Pode-se supor que não passa(va) pela intenção nem tampouco pelas elaborações dos curadores da mostra a compreensão de que a riqueza policromática das artes e da cultura brasileira, de suas gentes e de nossas paisagens sociais e culturais, de que a diversidade e a exuberância de nossas cores pudessem ser sublimadas, em conjunção e convergência, no branco.

De qualquer maneira e independentemente do que não se conseguiu alcançar, a mostra "A Cor do Brasil" pôde proporcionar encontros relevantes para aqueles/as visitantes que puderam deitar seus olhos e deleitar suas sensibilidades em obras que figuram com destaque na história da arte brasileira, como o Navio de Emigrantes de Lasar Segall (Fig. 4) e o Abaporú de Tarsila do Amaral, desde

OLIVEIRA, Luiz Sérgio de. Embates da descolonialidade e as pautas (não tão) ocultas dos museus: "A Cor do Brasil" no Museu de Arte do Rio.

PÓS:Revista do Programa de Pós-graduação em Artes da EBA/UFMG. v.10, n.20: nov.2020

Disponível em < https://doi.org/10.35699/2237-5864.2020.19685/>

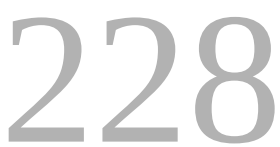


2001 na coleção do Museu de Arte Latino-Americana de Buenos Aires - MALBA (Fig. 5), entre outras obras que confirmam não apenas a riqueza da cor de nossa arte, mas, acima de tudo, a diversidade extraordinária das gentes que fecundam a cultura brasileira.

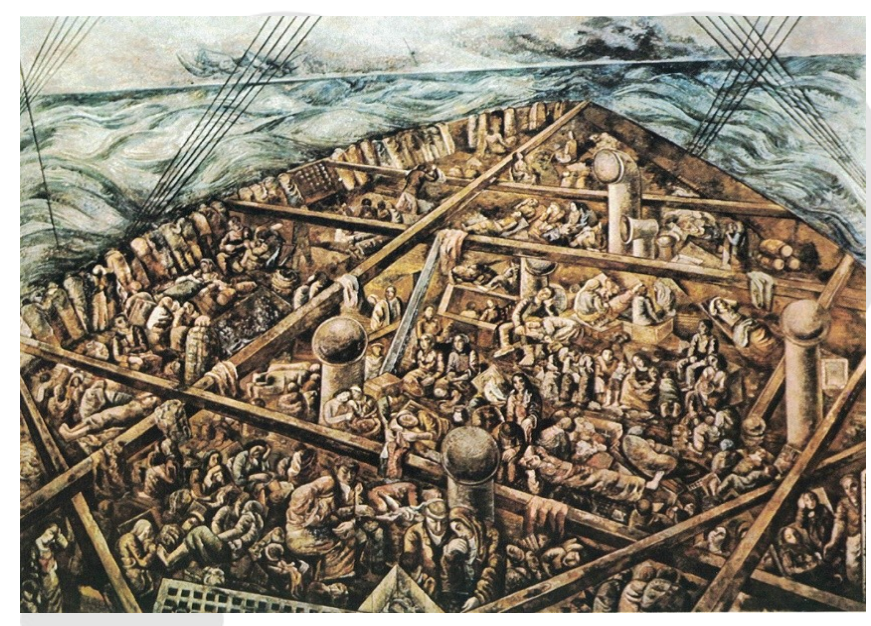

Fig. 4 - Lasar Segall, Navio de Emigrantes, 1939/41. Óleo com areia sobre tela, 230 × 275 cm. Coleção Museu Lasar Segall, São Paulo.Fonte: ZANINI, 1983, p. 575.

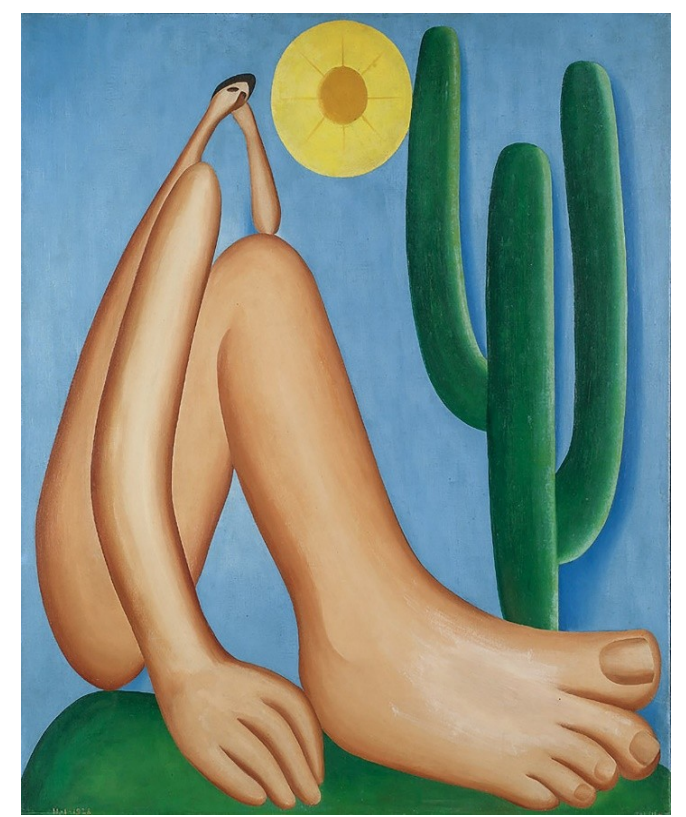

Fig. 5 - Tarsila do Amaral, Abaporú, 1928. Óleo sobre tela, 85,3 x 73 cm. Museo de Arte Latinoamericano de Buenos Aires - MALBA

Fonte: https://coleccion.malba.org.ar/abaporu/

OLIVEIRA, Luiz Sérgio de. Embates da descolonialidade e as pautas (não tão) ocultas dos museus: "A Cor do Brasil" no Museu de Arte do Rio.

PÓS:Revista do Programa de Pós-graduação em Artes da EBA/UFMG. v.10, n.20: nov.2020 Disponível em < https://doi.org/10.35699/2237-5864.2020.19685/>

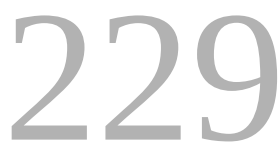




\section{REFERENCIAS}

AGAMBEN, Giorgio. O que é o contemporâneo? e outros ensaios. Chapecó: Argos, 2012.

BISHOP, Claire. Radical Museology, or, What's 'Contemporary' in Museums of Contemporary

Art? Londres: Koenig Books, 2013.

GÓMEZ, Pedro Pablo. O paradoxo do fim do colonialismo e a permanência da colonialidade.

Vazantes, v. 1, n. 2, p. 28-41, 2017.

GROYS, Boris. The Topology of Contemporary Art. In: SMITH, Terry; ENWEZOR, Okwui; CONDEE, Nancy (Ed.). Antinomies of Art and Culture: Modernity, Postmodernity, Contemporaneity. Durham e Londres, Inglaterra: Duke University Press, 2008. p. 71-80.

HERKENHOFF, Paulo; CAMPOS, Marcelo. A Cor do Brasil. [texto de apresentação da mostra, folder]. Rio de Janeiro: Museu de Arte do Rio, 2016.

LATOUR, Bruno. Jamais fomos modernos: Ensaio de Antropologia Simétrica. Rio de Janeiro: Editora 34, 1994.

MAR, Museu de Arte do Rio. A Cor do Brasil, 2016. Disponível em:

<https://www.youtube.com/watch?v=BOsPFHwlYC0\&t=444s>. Acesso em: 15 fev. 2020.

MAR, Museu de Arte do Rio. A Cor do Brasil. Textos da mostra, 2016. Arquivos do MAR. Disponível em: <https://museudeartedorio.org.br/sites/files/textos_a_cor_do_brasil_final >. Acesso em: $10 \mathrm{fev}$. 2020.

MENEZES NETO, Hélio Santos. Entre o visível e o oculto: a construção do conceito de arte afrobrasileira. 2018. 235 f. Dissertação (Mestrado em Antropologia). Faculdade de Filosofia, Letras e Ciências Humanas, Universidade de São Paulo, São Paulo, 2018.

MIGNOLO, Walter D. Museus no horizonte colonial da modernidade: Garimpando o museu (1992) de Fred Wilson. Museologia \& Interdisciplinaridade, v. 7, n. 13, p. 309-324, 2018.

MIGNOLO, Walter. D. Colonialidade: o lado mais escuro da modernidade. Revista Brasileira de Ciências Sociais, v. 32, n. 94, p. 1-18, 2017.

QUIJANO, Aníbal. Colonialidad del poder y clasificación social. In: Cuestiones y horizontes: de la dependencia histórico-estructural a la colonialidad/ descolonialidad del poder (seleção dos textos por Danilo Assis Clímaco) Buenos Aires: Clacso, 2014. p. 285-327.

VIVEIROS DE CASTRO, Eduardo. A inconstância da alma selvagem. São Paulo: Ubu Editora, 2017. ZANINI, Walter (Org.). História geral da arte no Brasil. São Paulo: Instituto Walther Moreira Salles, 1983. 2 v.

OLIVEIRA, Luiz Sérgio de. Embates da descolonialidade e as pautas (não tão) ocultas dos museus: "A Cor do Brasil" no Museu de Arte do Rio.

PÓS:Revista do Programa de Pós-graduação em Artes da EBA/UFMG. v.10, n.20: nov.2020

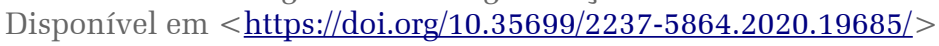

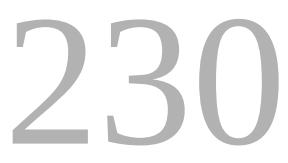




\section{NOTAS}

1 Este trabalho é parte do projeto de pesquisa Última saída para o museu (des)colonial: um olhar investigativo sobre o Museu de Arte do Rio, que conta com apoio e suporte financeiro do Conselho Nacional de Desenvolvimento Científico e Tecnológico (CNPq), através do Programa de Bolsa de Produtividade em Pesquisa. O projeto conta ainda com a colaboração de Isabelle Machado, graduanda do Bacharelado em Artes da Universidade Federal Fluminense, bolsista do Programa Institucional de Bolsas de Iniciação Científica (PIBIC) do CNPq. Nossos agradecimentos ao CNPq. Expressamos também nossos agradecimentos à equipe do Museu de Arte do Rio - MAR, em especial a Evandro Salles, Diretor Cultural do MAR à época, e a Amanda Bonan, Coordenadora de Curadoria e Pesquisa do MAR.

2 A exposição “A Cor do Brasil" esteve em cartaz no Museu de Arte do Rio, Rio de Janeiro, entre o dia 2 de agosto de 2016 e 15 de janeiro de 2017. Com curadoria de Paulo Herkenhoff e Marcelo Campos, a mostra reuniu mais de 300 obras de autoria de mais de 200 artistas, dentre os quais podemos consignar: Aluísio Carvão, Anita Malfatti, Anna Bella Geiger, Anna Maria Maiolino, Antônio Dias, Antonio Gomide, Arthur Luiz Piza, Bandeira, Barsotti, Bruno Lechowski, Carlos Vergara, Carybé, Cristina Canale, Décio Vieira, Eduardo Sued, Flávio de Carvalho, Franz Post, Franz Weissmann, Geraldo de Barros, Goeldi, Gonçalo Ivo, Guignard, Hélio Oiticica, Henrique Bernardelli, Hermelindo Fiaminghi, Iberê Camargo, Ismael Ney, Ivan Serpa, Joaquim Tenreiro, Jorge Guinle, José Maria Dias da Cruz, José Pancetti, Judith Laund, Julio Leite, Katie van Scherpenberg, Lasar Segall, Lothar Charoux, Luis Sacilootto, Lygia Pape, Mabe, Manfredo Souzaneto, Milton Dacosta, Osmar Dillon, Portinari, Quirino Campofiorito, Roberto Magalhães, Rubens Gerchmann, Shiró, Tomie Ohtake, Tunga, Vicente do Rego Monteiro, Waldemar Cordeiro, Waltércio Caldas, Wanda Pimentel e Willys de Castro.

3 Texto de parede aplicado no contexto da mostra "A Cor do Brasil": "O Brasil é nomeado por uma cor abrasante. O país surge da exploração econômica da cor, o pau-brasil. A espessura da carta de Pero Vaz de Caminha, a certidão de nascimento do Brasil, se escreve por imagens cromáticas: copazinha de penas vermelhas, continhas brancas, pardos à maneira de avermelhados, cabeleira de penas amarelas, papagaio pardo, quartejados de cores, tintura preta, a modos de azulada, e outros quartejados de escaques, carapuças vermelhas, carapuças de penas amarelas, outros, de vermelhas, e outros de verdes, a tintura era assim vermelha, tintura preta, pedra verde, carapuça vermelha, choupaninhas de rama verde, barretes de penas de aves, deles verdes e deles amarelos, ouriços verdes, grãos vermelhos pequenos, papagaios vermelhos, muito grandes e formosos, e dois verdes pequeninos e carapuças de penas verdes, e um pano de penas de muitas cores, cera vermelha. (Fonte: Arquivo do Museu de Arte do Rio, Rio de Janeiro). 